\title{
PERBANDINGAN SHALAT DAN LAKU MANEMBAH ALIRAN KEBATINAN PANGESTU DAN SUMARAH
}

\section{Rosmaria Syafariah Widjayanti}

UIN Syarif Hidayatullah Jakarta

Diterima tanggal 25 Pebruari 2015 / Disetujui tanggal 16 Maret 2015

\begin{abstract}
Adherents of Islam on Java community can be distinguished by the adherents of Islam who are santri or abangan. Muslim santri are adherents of Islam are actually based on the Koran, while the abangan Islam is a follower of Islam that unites the elements of local cultural beliefs and previous pre-Hindu, Hindu Islamic beliefs. Adherents of this syncretic Islam due to the influence and dynamism animissme ancestor's life and under the influence of Hinduism who entered the archipelago before the arrival of Islam.
\end{abstract}

Kata kunci: Islam, Penganut, Nusantara.

\section{Pendahuluan}

Aliran kebatinan secara antropologis merupakan sistem kepercayaan yang dianut oleh sebagian masyarakat Indonesia,khususnya masyarakat Jawa. Oleh karena itu kebatinan sering disebut "kejawen" atau "javanisme”. Gerakan Aliran kebatinan muncul sebagai bagian dari gerakan revolusi di Indonesia pada bidang moral spiritual. Munculnya gerakan kebatinan ini didorong oleh keingin melakukan kritik terhadap gerakan-gerakan agama besar di Indonesia,terutama Islam dan kristen,yang seharusnya banyak berbuat, tetapi kurang memperlihatkan peranannya sebagai kekuatan moral spiritual. ${ }^{1}$

Menurut Mulder kebatinan pada dasarnya adalah mistik, penembusan dan pengetahuan mengenai alam raya dengan tujuan untuk mengadakan suatu hubungan secara langsung individu dengan Lingkungan Yang Maha Kuasa. ${ }^{2}$ Sedangkan kebatinan dalam masyarakat Jawa dianggap sebagai gaya hidup (spiritual) yang ditujukan menyelaraskan hubungan dirinya dengan Tuhan. Contoh mengenai aliran kebatinan ini adalah Paguyuban Ngesti Tunggal (Pangestu) dan Paguyuban Sumarah.

Penganut Islam pada masyarakat Jawa beragam yang dapat dibedakan dengan penganut agama Islam yang secara santri maupun sinkretis.Islam santri adalah penganut Islam yang benarbenar didasari oleh al-Quran, sedangkan Islam sinkretis adalah penganut Islam yang menyatukan unsur-unsur keyakinan dan kebudayaan lokal sebelumnya yaitu pra-Hindu, Hindu dengan keyakinan Islam.Penganut Islam sinkretis ini akibat pengaruh animissme dan dinamisme kehidupan nenek moyang dan akibat pengaruh agama Hindu yang masuk ke Nusantara sebelum kedatangan Islam. Simuh menyatakan bahwa Islam sinkretis ini memuja roh nenek moyang sertapercaya pada kekuatan gaib pada benda,tumbuh-tumbuhan, binatang. Kekuatan yang

${ }^{1}$ Suwarno Imam S, Konsep Tuhan, Manusia, Mistik dalam Berbagai Kebatinan Jawa, (Jakarta: PT Raja Grafindo Persada, 2005), h. ix.

${ }^{2}$ Arsip Sardjana Budi Santoso, (Jakarta: Proyek Penerbitan dan Perpustakaan Pangestu Pusat, 1973), h. 14. 
terdapat pada sekelilingnya ini dianggap memiliki daya kesaktian. Kepercayaan dan pemujaan seperti keagamaan seperti itu, akibat pengaruh agama dan kebudayaan Hindu.

Dalam praktek pelaku Islam yang besifat sinkretis ini terdapat laku yang bersifat dasar spiritual. Laku ini dipahami sebagai cara hidup yang serba prihatin dijalankan oleh penganut Islam sinkretis untuk mencapai kesempurnaan hidupatau kasampurnan.Cara yang dilakukan dengan menjalani hidup dengan prihatin dan menghindari kehidupan yang berhubungan dengan keduniawian. Laku yang dilaksanakan seperti bertapa brata, puasa, dan pati geni.

Di atas telah disinggung bahwa Indonesia terdapat bermacam-macam aliran kebatinan dan kepercayaan, di antara sekian banyak aliran tersebut kebanyakan terdapat di pulau Jawa. Dilihat dari karakteristik penduduk Jawa, yang memiliki tipe masyarakat yang menyukai kerukunan, selaras dan hidup damai, menyebabkan tersebarnya aliran kebatinan dengan cepat, maka budaya "kejawen", kebanyakan berkembang di Jawa, khususnya di Jawa Tengah dan Yogyakarta”. Kebatinan atau kejawen ini misalnya Kawula Wargi Naluri, yang berasal dari Gandrungmangun Banyumas.

Dari banyaknya aliran kebatinan di Jawa ini memiliki cara atau pola dalam berbakti kepada Tuhan. Seperti ritual-ritual dalam agama samawi (Islam), mereka juga memiliki cara menyembah kepada Tuhan. Konsep ritual ini sering dinamakan dengan menyembah atau manembah. Dalam kajian ini manembah dibatasi dalam aliran kebatinan pangestu dan sumarah.

Manembah adalah bentuk pengabdian atau berbakti pada sesuatu. Manembah berasal dari kata sembah yang maksudnya berbakti. Manembah berbakti pada sesuatu yang lebih besar dari padanya. Gambaran mengenai hal ini dapat dilihat dari tradisi menyembah pada raja dalam kesenian tradisional Jawa, Sungkem pada orang tua. Dalam bentuk yang sama pengertian manembah di sini berbakti pada Tuhan, sebagai sesuatu yang lebih besar darinya.

Manembah dilakukan oleh aliran kebatinan. Aliran kebatian merupakan suatu kenyataan bahwa kepercayaan (kebatinan, kejiwaan dan kerohanian) bagi bangsa Indonesia telah merupakan suatu naluri dan dapat merupakan kebudayaan kita yang akhir-akhir ini dikalangan generasi muda kabur dan kurang mendapat perhatian, yang sebenarnya dengan jalan inilah manusia dapat memahami "rasa" daripada kehidupan itu sendiri.

Dalam Islam ada istilah beribadah. Ibadah dalam Islam tidak sekedar menjalankan ritusritus yang diwajibkan seperti ibadah shalat, puasa, zakat, dan haji. Ibadat dalam pengertian Islam adalah berserah diri hanya kepada Allah swt. Melaksanakan perintah dan larangan Nya yang termaktup dalam ketentuan yang telah ditetapkan dalam kitab suci. Dalam Islam ibadah ritual dalam bentuk shalat yang didalamnya terdapat tata cara seperti yang terdapat rukun dan syarat sahnya shalat. Tata cara yang terkait fisik seperti gerakan-gerakan shalat, berdiri, takbir, rukun, sujud. Disamping gerakan fisik terdapat doa, karena shalat pada dasarnya adalah doa.

\section{Kebatinan Pangestu Dan Sumarah}

Paguyuban Ngesti Tunggal yang dikenal dengan nama Pangestu merupakan budaya kebatinan yang sangat luas pengaruhnya. Aliran ini dipelopori oleh Soenarto yang pernah menerima wangsit yang kemudian dibukukan dalam buku Sasangka Jati. Aliran Pangestu didirikan oleh Soenarto selama 28 tahun (1932-1961). Tokoh ini menjadi perantara dari Sang Guru Sejati yang kemudian disusun menjadi Kitab, antara lain Sabda Pratama,Sasangka Jati 
dan Sabda Khusus.

Paguyuban Sumarah merupakan organisasi besar yang tumbuh dari Yogyakarta. Organisasi ini dimulai dari gerakan kecil yang dipimpin oleh R.Ng Sukirnohartono yang mengaku menerima wahyu pada tahun 1935. Akhir tahun 1940-an gerakan itu memudar namun berkembang kembali pada tahun 1950 di daerah Yogyakarta. Anggota-anggota berkembang dan kini jumlah anggotanya mencapai 115.000 orang lebih, baik yang berasal dari kalangan priyayi maupun dari kelas-kelas masyarakat lain. ${ }^{3}$ Paguyuban Sumarah yang juga disebut dengan ilmu Sumarah adalah suatu kebatinan yang dilaksanakan dengan jalan sujud sumarah (penyerahan diri) mempelajari dan mengusahakan sampai bersatunya jiwa dengan Zat Yang Maha Esa. Pokok ajaran Paguyuban Sumarah adalah sujud. Harun Hadiwiyono menyatakan sujud dikalangan paguyuban Sumarah ini diartikan dengan "perseketuan dengan Tuhan". ${ }^{4}$ Sumarah dalam makna dari bahasa Jawa adalah pasrah atau berserah diri yang dekat dengan pengertian Islam atau berserah diri pada Tuhan yang maha Esa.

Sumarah merupakan filsafat hidup dan suatu bentuk meditasi.Pada kenyataannya, meditasipada aliran Sumarah merupakan kepekaan dan penerimaan melalui relaksasi tubuh, perasaan dan pikiran, sehingga tercipta ruang di dalam diri seseorang, yang dalam batinnya terjadi kesunyian, yang bertujuan untuk mewujudkan jati diri dalam diri pelaku. Sumarah dilakukan dengan melalui cara meditasi.Pada Paguyuban Sumarah, meditasi merupakan cara untuk membantu manusia berjalan di dunia dengan jalan yang terbaik. Meditasi adalah sebuah cara untuk membantu manusia berhenti dan ingat kepada Tuhan melalui keheningan dirinya.

Konsep Manembah menurut aliran Pangestu adalah keharusan bagi yang ingin bertemu dengan Tuhan dalam batinnya. Dengan manembah ini maksudnya adalah menumbuhkan nilai ke-Allah-an, agar dalam batin hidup semangat ketuhanan dengan sadar (ingat), percaya, dan taat. ${ }^{5}$ Perasaan religius seperti ini merupakan salah satu unsur penting bagi umat beragama atau kaum mistik, yang disebut pengalaman beragama. Pengalaman religius (Religius experience) merupakan unsur yang penting dari perasaan dan membawa keyakinan yang dihasilkan oleh tindakan (amaliah). ${ }^{6}$

\section{Laku Panembah Menurut Aliran Sumarah}

Paguyuban Sumarah memiliki konsep ketuhanan yang sederhana.Penerimaan terhadap Kepercayaan kepada Tuhan tampak diterirna begitu saja, tanpa ada syarat.Tuhan Yang Maha Esa pada Paguyuban Sumarah disebut Tuhan Allah. Konsep tentang Tuhan di dalam Sumarah dan kebanyakan pada semua aliran kebatinan bisa dikatakan monisme panteistik, yaitu Tuhan dan manusia dilihat sebagai satu kesatuan. Imanensi Tuhan secara total adalah sangat jelas, Tuhan berada pada posisi di dalam diri yang manusia diwakili oleh urip (hidup). Dinyatakan bahwa urip (hidup) itu hakikatnya adalah Tuhan itu sendiri. Seperti pada umumnya keyakinan bangsa Indonesia, manusia menurut Paguyuban Sumarah terdiri atas 2 hal yaitu jasmani (badan)

\footnotetext{
${ }^{3}$ Budaya Kebatinan, http//www.kikil.org/forum).

${ }^{4}$ Harun Hadiwijono, Konsep Tentang Manusia dalam Kebatinan Jawa, (Jakarta: Sinar Harapan, 1983), h. 103.

${ }^{5}$ R. Soenarto Mertowardojo, Sasangka Jati, (Jakarta: Badang Penerbitan dan Perpustakaan Pangestu Pusat, 1983), h .182 .

${ }^{6}$ Zakiah Daradjat, Ilmu Jiwa Agama, (Jakarta: Bulan Bintang, 1991), h. 4.
} 
dan jiwa (roh). Badan berasal dari empat anasir, yaitu: bumi, angin, air, dan api. Badan telah dianugerahi peralatan pancaindera, dilengkapi dengan pemikir, nafsu, angan-angan, suksma, dan nyawa.Antara pemikir dan angan-angan berhubungan erat sekali.Hal-hal yang ditangkap oleh pemikir kemudian sampaikan kepada angan-angan untuk disimpan. ${ }^{7}$

Sumarah mengutamakan akhlak dalam ajarannya.Pengendalian terhadap nafsu memegang peran penting. Terkait nafsu, ilmu sumarah menggolongkan empat macam, yaitu lawamah bersifat mementing kan diri, amarah bersifat kemarahan, suwiyah bersifat erotis, dan mutmainah bersifat kebaikan. Nafsu ini disebut suksma, sedangkan pemikir, angan-angan, nafsu dan suksma disebut nyawa atau jiwa dalam arti psikologis. Jiwa atau roh berasal dari Allah, yang dibaratkan sebagai pletikan (bunga api) dari-Nya. Roh berhubungan erat dengan zat yang terdapat dalam dada, yaitu sanubari.Bagian yang lebih dalam adalah qalb atau hati yang terdapat di dalam jantung.Di dalam qalb tersebut terdapat Masjidil Haram tempatnya Baitullah.Di dalam Baitullah ini terdapat budi, nur, dan urip atau hidup. ${ }^{8}$ Sedangkan badan dan alat kelengkapan badan digolongkan pada dunia yang tampak di permukaan atau alam wadag.Di bandingkan dengan badan, jiwa dan rasa bagian dari alam gaib yang dimensinya lebih luas dari dunia yang tampak.Alam gaib lebih luas lagi meliputi alam wadag dan alam gaib.Alam gaib disebut juga sebagai alam bayangan, yang letaknya di dalam jantung.

Sumarah memberikan ajaran kepada diri anggotanya berupa tuntunan untuk mengubah sistem parlementer menjadi sistem presidential, yaitu melalui jalan sujud sumarah atau menyerahkan diri.Sujud sumarah merupakan jalan untuk mencapai persatuan antara jiwa dengan Tuhan.Sujud sebagai jalan menuju Tuhan tersebut menurut Sumarah terdiri atas empat tingkatan, yaitu.

Pertama disebut Sujud Raga, yaitu persatuan manusia dengan Allah melalui perantaraan badan wadag. Pada tingkatan ini angan-angan mewakili raga (badan wadag) yang dipergunakan sebagai alat untuk melakukan sujud. sujud dilaksanakan dengan jalan memisahkan angan-angan dari pemikir. Seseorang yang telah berhasil memisahkan angan-angan dari pemikir, maka anganangan tersebut diturunkan dari otak ke sanubari. Angan-angan tersebut tidak dapat dipakai untuk berpikir lagi. Kegiatan sujud ini dibantu dengan menjalankan zikir, dengan menyebut nama-nama Allah. ${ }^{9}$

Kedua, Sujud Jiwa Raga. Pada tingkatan kedua ini angan-angan yang telah dipisahkan dari pemikir, kemudian diturunkan ke sanubari dan didekatkan dengan rasa yang terletak di dalam dada. Kedua angan-angan dan rasa tersebut dapat melakukan sujud berdampingan. Dalam hal ini rasa menjadi wakil jiwa. Sujud yang dilakukan raga dan rasa ini yang menyebabkan tingkatan kedua sujud disebut dengan Sujud Jiwa Raga.Keberhasilan sujud ini merupakan kunci pertama dalam Sujud Sumarah yaitu persatuan jiwa raga dengan Allah dengan bentuk penyerahan diri. Apabila pada tingkatan sujud ini berhasil dan sering dilakukan maka ada kemungkinan orang tersebut akan menerima sabda Tuhan atau dikenal dengan dawuh hakiki. Dawuh hakiki adalah mendengar sebuah suara yang mendadak. Namun demikian, orang yang mencapai taraf seperti

\footnotetext{
${ }^{7}$ Suwarno Imam S, Konsep Tuban..., h. 211.

${ }^{8}$ Harun Hadiwijono, Konsep Tentang Manusia..., h.106.

${ }^{9}$ Suwarno Imam S, Konsep Tuhan..., h. 223.
} 
ini harus berhati-hati sebab masih harus dapat membedakan dengan bahaya tipuan iblis, seperti bisikan iblis. Tingkatan kedua sujud ini diulangi setiap saat dan dimana tempat, sehingga akan rnenjadi terbiasa melaksanakan sujud. Melalui cara demikian ini maka angan-angan menjadi menyatu dengan rasa.

Pada tingkatan ketiga adalah Sujud tetap Iman. Maksudnya adalah sujud yang dilaksanakan secara terus-menerus tanpa henti. Pada tingkatan sujud ini, sesorang dapat menerima sabda Tuhan tanpa dibatasi tempat, waktu, dan keadaan. Dimanapun dan kapanpun orang dapat sujud.Sujud ini dapat digambarkan seperti orang yang telah lancar naik sepeda. Berbeda dengan orang yang baru belajar naik sepeda yang masih harus konsentrasi memperhatikan gerak badan, kaki serta tangan. Namun orang yang telah lancar naik sepeda, maka perhatiannya tidak lagi pada gerak seluruh badan. Misalnya, orang tersebut dapat naik sepeda sambil menyanyi. Sujud yang telah lancar dalam keadaan apapun dia dapat melaksanakan sujud. ${ }^{10}$ Pada tingkatan keempat, adalah Sujud Sumarah, yaitu sujud dengan jalan penyerahan diri kepada Tuhan. Sujud tingkatan ini merupakan sujud yang tertinggi, karena dalam konsidi ini orang berada dalam kondisi menyatu dengan Tuhan (Jumbuhing kawula Gusti). Kondisi ini tidak dimaksudkan jiwa manusia larut ke dalam Tuhan, tetapi antara jiwa manusia dan Tuhan dalam keadaan kesatuan kehendak. Kondisi seperti ini tidak setiap orang dapat mencapainya.Karena merupakan anugerah dari Tuhan yang diberikan kepada seseorang secara tiba-tiba.Seseorang yang menerima anugerah menyatu ini tiba-tiba merasa bahwa sujudnya telah dipindahkan dari sanubari ke jantung, dimana tempat qalb berada.Sujud terasa untuk sesaat saja, kemudian lenyap, sehingga tidak merasakan apa-apa.Rasa sujud tersebut lenyap karena antara keduanya (hamba dan Tuhan), sudah menjadi satu sehingga tidak ada lagi pihak yang bersujud dan pihak yang disujudi.Kondisi ini yang disebut Jumbuhing kawula Gusti. Paguyuban Sumarah menyebut kondisi ini sebagai Gambuh. ${ }^{11}$

Untuk mencapai sujud Sumarah ini seseorang harus melaksanakan tiga syarat Sumarah, yaitu tidak melaksanakan apa-apa, tidak memiliki apa-apa, dan menyerahkan jiwa dan raga. Dalil pertama, yaitu tidak berbuat apa-apa, maksudnya adalah orang tersebut tidak bisa berbuat apa-apa, kecuali karena kehendak Allah.Anggota Paguyuban Sumarah tidak boleh sombong yang berlagak dapat berbuat apapun. Merasa lebih daripada orang lain, merasa semua yang ada sebagai kekayaannya. Tidak boleh kumingsun, maksudnya merasa dirinya sebagai ingsun seperti orang yang paling penting.Hal ini karena yang menganggap dirinya dapat melakukan segala sesuatu. Orang yang dapat berserah ini akan dapat memecahkan segala kesulitan yang dihadapi melalui jalan menyerahkan diri kepada Allah. ${ }^{12}$

Syarat kedua adalah tidak memiliki apa-apa. Maksud tidak memiliki apa-apa sama dengan pepathah Jawa, yaitu sepi ingpamrih, rame ing gawe, maksudnya iklas, dan kerja keras. Segala yang ada ini milik Tuhan, termasuk di dalamnya tubuh dan jiwa seseorang.Segala yang ada merupakan pinjaman oleh Tuhan untuk manusia.Maka apabila terdapat barang yang hilang, mestinya dipahami bahwa batas waktu barang yang dipinjamkan telah usai. Dengan perasaan seperti ini, orang tidak kecewa dan dapat menerima dengan senang hati.

\footnotetext{
${ }^{10}$ Suwarno Imam S, Konsep Tuban..., h. 224.

${ }^{11}$ Harun Hadiwijono, Konsep Tentang Manusia..., h. 22.

${ }^{12}$ Suwarno Imam S, Konsep Tuhan..., h. 225.
} 
Syarat ketiga adalah menyerahkan jiwa-raga.Syarat ini sebagai lanjutan dari syarat kedua. Dengan melaksanakan syarat ketiga tersebut, di dalam batin seseorang mengalami proses yang semakin mendekati manunggal jiwa dengan Tuhan. Di sini terdapat kejadian bahwa seseorang menerima sabda Allah.Pada mulanya sabda tersebut diterimaa dengan perantaraan rasa, kemudian dengan adanya suara yang ada di dalam batin, dan akhirnya orang tersebut menerima sabda itu dengan perantaraan mulut atau alat lainnya. Sabda seperti ini disebut wajibul wujud, maksudnya mengetahui segala sesuatu tanpa pemberitahuan atau dalam bahasa jawa mengerti tanpo dawuh. ${ }^{13}$

Dari uraian konsep sujud Paguyuban Sumarah dapat dibahas dari kacamata paradigma sinkretisme. Pertama, kata "Sumarah" dapat dilihat dari tiga konteks : yaitu Paguyuban Sumarah, Ilmu Sumarah, dan Sujud Sumarah. Ketiga hal tersebut memiliki makna tersendiri. Konteks Paguyuban Sumarah berkaitan dengan nama sebuah organisasi kerohanian. Paguyuban memiliki makna kerukunan atau perkumpulan. Kemudian Ilmu Sumarah berhubungan dengan ilmu kebatinan. Ilmu Sumarah adalah ilmu kebatinan yang dilaksanakan melalui jalan Sujud Sumarah atau menyerahkan diri sampai mencapai manunggal jiwa manusia dengan Tuhan. ${ }^{14}$ Sedangkan Sujud Sumarah berhubungan dengan tingkatan-tingkatan sujud.Ketiga konteks tersebut mengacu kepada kata "Sumarah", kata dalam bahasa Jawa yang identik dengan arti kata "islam" dalam pengertian berserah diri.Hal ini nampak Sumarah sebagai aliran kebatinan, dari sudut bahasa, merupakan terjemahan dari kata "islam".

Empat tingkatan sujud ajaran Paguyuban Sumarah terrsebut, yaitu sujud raga, sujud jiwa raga, sujud tetap iman, dan sujud sumarah, hampir sama dengan empat tingkatan sujud yang terdapat dalam Serat Wedatama karya Mangkunegara IV (1811- 1881), yaitu yang dinamakan dengan istilah sembah raga, sembah cipta, sembah jiwa, dan sembah rasa. Istilah ini terdapat pada Pupuh IV Gambuh bait I, baris 3 sebagai berikut:

Sumengko ingsun tutur (Sekarang saja mengajarkan)

Sembah catur supaya lumuntur (Empat sembah supaya diwariskan).

Dhikir raga cipta jiwa rasa kaki (Yang pertama sembah raga, cipta, jiwa, rasa, wahai anakku

Ingkono lamun ketemu (Di situ apabila dapat ketemu)

Tandha nugrahaning Manon (Tanda memperoleh anugerah Tuhan)

Empat tingkatan sujud Paguyuban Sumarah yang berperan sebagai jalan menuju kesempurnaan, yaitu : sujud raga, sujud jiwa raga, sujud tetap iman, dan sujud sumarah, juga menyerupai empat jalan menuju kepada Tuhan yang terdapat tradisi tasawuf, terutama dalam literatur Hamzah Fansuri. Menurut Hamzah Fansuri disebut sebagai tingkatan: syari'at, tarikat, haqiqat, dan ma'rifat. Juga menyerupai empat tingkat menurut Syamsudhin Sumatrani, yaitu Islam, Iman, Tauhid, dan Makrifat. Menurut Paguyuban Sumarah, tingkatan sujud pertama ini disebut sujud kanoman, sedangan tingkatkan kedua disebut sujud kasepuhan. Istilah tingkatan sujud trersebut terdapat di dalam aliran kebatinan Pangestu yang disebut dengan "Panembah raga kepada roh suci", sebagai penembah pada jiwa yang masih muda dan "Panembah roh suci kepada Suksma Sejati” sebagai panembah pada jiwa yang telah dewasa.

\footnotetext{
${ }^{13}$ Suwarno Imam S, Konsep Tuban..., h. 226.

${ }^{14}$ Harun Hadiwijono, Konsep Tentang Manusia..., h. 13.
} 
Kesempurnaan adalah taraf yang paling tinggi. Seseorang apabila telah berhasil mencapai taraf demikian maka orang tersebut telah mencapai jumbuhing kawula Gusti atau kesatuan hamba dengan Tuhannya. Sudah terjadi kesatuan kehendak antara jiwa seorang manusia dengan Tuhannya. Konsep manusia sempurna seperti ini terdapat dalam literatur Islam tasawuf, seperti pendapat Ibn al-Arabi, yaitu manusia yang telah berakhlak dengan akhlak Allah (al-takhaluq bi akhlaq Allah). Adapun perbedaan antara keduanya adalah kondisi kesempurnaan ini menurut Paguyuban Sumarah menggunakan kalimat "kehendak", sedangkan menurut Ibn al-Arabi menggunakan kata "akhlak". Kondisi jumbuhing kawula Gusti tersebut sebagai sujud di dalam hidup, dimana tidak terdapat pihak yang bersujud dan pihak yang disujudi, karena telah menjadi satu. ${ }^{15}$ Pengertian ini juga hampir sama dengan istilah fana yang terdapat dalam literatur tasawuf. Tepatnya alfana an al-najs, yang artinya leburnya kesadaran akan wujud dirinya, yang ada adalah wujud rohaninya, yaitu kondisi ketika seseorang dapat bersatu dengan Tuhan. Taraf jumbuhing kawula Gusti ini merupakan anugerah dari Tuhan, yang di dalam Serat Wedatama disebut tandha nugrahaning manon. Seseorang yang memperoleh anugerah jumbuhing kawula Gusti ini, datang dengan mendadak dan hanya sesaat saja, kemudian perasaan ini lenyap lagi. Keadaan seperti ini juga menyerupai tradisi taswwuf yang disebutkan dalam literatur tasawuf, yang dipahami sebagai anugerah yang berasal dari Allah, bersifat sementara, yang datang, dan pergi tanpa diduga. ${ }^{16}$

\section{Laku Panembah Menurut Pangestu}

Pengertian Tuhan menurut Pangestu terdapat dalam penjelasan pada kitab Sasangka Jati. Keadaan Tuhan Yang Mahatunggal disebut Tri Purusa, yang berarti keadaan satu namun memiliki sifat tiga, yaitu: ${ }^{17}$

a. Suksma Kawekas atau Tuhan sejati. Dalam bahasa Arab Allah ta'ala

b. Suksma Sejati atau pemimpin sejati, yang sama pengertiannya dengan penuntun sejati atau Guru Sejati, bisa juga di artikan utusan Tuhan

c. Roh suci atau manusia sejati, yaitu merupakan jiwa manusia yang sejati. ${ }^{18}$

Dalam kitab Sasangka Jati dijelaskan tentang pengertian Suksma Kawekas, Suksma Sejati, dan Roh Suci.Suksma mengandung pengertian yang menghidupi atau yang membuat hidup, yang menyebabkan manusia memiliki rasa hidup.Sehingga kata Suksma Kawekas merupakan suksma yang terluhur.Kemudian kata ini memiliki arti Yang Maha menguasai hidup atau yang menguasai kehidupan sesungguhnya. Pengertian kata Suksma Sejati adalah: sesungguhnya yang menghidupi. Yang dihidupi adalah Roh Tuhan (Roh Suci), yaitu jiwa manusia, yang diberi selimut pakaian berupa 4 anasir. Suksma Kawekas adalah suksma yang paling luhur, Yang Mahakuasa, yaitu yang menguasai hidup. Suksma Sejati adalah yang sesungguhnya menghidupi, sedangkan Roh Suci adalah yang dihidupi, yaitu jiwa manusia yang sejati. Untuk jelasnya pengertian ini dalam kitab Sasangkajati terdapat penjelasan tentang Syahadat Islam yang mengandung pengetian Allah-Rasul-Muhammad, sebagai berikut: Syahadat tauhid dan syahadat Rasul yaitu Asybadu

\footnotetext{
${ }^{15}$ Suwarno Imam S, Konsep Tuhan..., h. 228.

${ }^{16}$ Suwarno Imam S, Konsep Tuhan..., h. 229.

${ }^{17}$ Suwarno Imam S, Konsep Tuban..., h. 300.

${ }^{18}$ R. Soenarto Mertowardojo, Sasangka Jati, h. 13.
} 
anla ilaha illa Allah, wa asyhadu ana Muhammada Rasulallah. Pertanyaanya adalah siapakah sejatinya Muhammad itu? Muhammnad itu Nur Muhammad, nur Muhammad itu nur Zat Allah, dimana cahayanya tidak dapat diserupakan dengan apa pun, yang meresap ke dalam keadaan tunggal, masuk ke dalam tempat bertunggalnya hamba dengan Tuhan (pamoring kawula Gusti). Para ahli makrifat menyebut teluning ngatunggal (Allah-Rasul-Muhammad) yang lebur jadi satu. ${ }^{19}$ Kemudian di dalam Sasangka jati dijeasakan bahwa Nur Muhamrnad juga disebut Kristus atau Sang Putra, dengan penjelasan berikut: Adapun Nur Muhammad juga disebut Kristus dalam agama Kristen atau disebut Sang Putra, adalah sejatinya Rasulallah atau utusan yang abadi. Istilah Putra Allah atau Allah Sang Putra mengandung arti bukan berarti Tuhan Allah mempunyai anak bilogis. Tuhan anak mengandung arti sifat Kasih Tuhan, ibarat kasih bapak berada pada anaknya. ${ }^{20}$

Sesuai dengan pendapat di atas, Sumantri menyamakan Suksma Kawekas dengan Sang Rama dan Suksma Sejati dengan Sang Putra. Menurutnya Kesadaran Agung bersuasana kasih sayang, oleh karenanya kasih sayang yang terdapat dalam Suksma Kawekas sama sekali dilimpahkan kepada anaknya. Maka melihat perimbangan Suksma Kawekas adalah Sang Rama dan Suksma Sejati disebut Sang Putra. ${ }^{21}$

Menurut Sumantri, dalam Sasangka Jati sangat jelas tidak dibedakan antara istilah: AllahRasul-Muhammad atau Sang Rama-Sang Putra-Roh Suci, atau Suksma Kawekas-Suksma SejatiRoh Suci, seperti dalam kutipan berikut: Intisarinya tidak ada beda hakikat yang disebut AllahRasul-Muhamrnad atau Sang Rama - Sang Putra - Roh Suci, seperti ajaran-Ku yang disebut Suksma Kawekas-Suksma Sejati-Roh Suci. ${ }^{22}$

Pengertian Tri Purasa dapat dilihat dari identifikasi dengan Allah-Rasul-Muhammad dan dengan Sang Rama-Sang Putra-Roh Suci. Kedudukan Tri Purusa berada di tengah antara ajaran ahli makrifat ala Pangestu dan ajaran Trinitas agama Kristen. Sumantri menafsirkan Tri Purusa dengan keadaan Tuhan Yang Mahatunggal, sumber hidup atau hidup asal yang abadi, immateril, rnerembes-menembus dan meliputi segala sesuatu. Asal hidup pada hakikatnya adalah satu, yang menampakkan diri dalam tiga aspek (faset).Pertama adalah tertinggi, mutlak, diam, dan statis yang disebut dengan Suksma Kawekas.Kedua adalah aspek hidup dinamis, yang dilahirkan dari yang statis, yang disebut dengan Suksma Sejati. Ketiga adalah Roh Suci atau jiwa sejati manusia, dianggap sebagai cahaya atau percikan api Suksma Kawekas. Inilah yang disebut dengan Tripurasa, yaitu hidup yang satu dan rnenampakkan diri dalam tiga aspek.

Dari pendapat Sumantri di atas dinayatakan bahwa Hidup Asal pada hakikatnya adalah satu, namun menampakkan diri dalam tiga fase. Konsep ini menyerupai konsep tajalli atau penampakan diri Tuhan yang biasa dijelaskan dalam literatur tasawuf. Konsep tajalli ini seperti penampakan diri Tuhan atau konsep fayd (emanasi) Ibn Al-'Arabi dan sufi-sufi yang lainnya. Menurut Ibn al-'Arabi Tajalli zati terdiri dari dua, yaitu martabat ahadiyah dan wahidiyah. Kemudian sufi lainnya yaitu Muhammad ibn Fadlullah al-Burhanpuri mengembangkan konsep tajalli Ibn al-'Arabi ini, yang dikenal dengan ajaran martabat tujuh, yaitu 1) ahadiyah, 2) wahdah atau nur muhammad, 3) wahidiyah, 4) alam arwah, 5) alam mitsal, 6) alam ajsam, 7) insan.

\footnotetext{
${ }^{19}$ R. Soenarto Mertowardojo, Sasangka Jati, h.101.

${ }^{20}$ R. Soenarto Mertowardojo, Sasangka Jati, h. 101.

${ }^{21}$ Suwarno Imam S, Konsep Tuhan..., h. 302.

${ }^{22}$ R. Soenarto Mertowardojo, Sasangka Jati, h. 101-102.
} 
Martabat wahdah ini serupa dengan nur Muhammad. Pendapat ini sama dengan martabat nur Muhammad yang terdpat dalam Wirid Hidayat Jati Ranggawarsita. Martabat ketiga yang diterangkan dalam Wirid Hidayat Jati, yaitu martabat mir'atul haya'i juga diserupakan dengan konsep pramana yang terdapat dalam Serat Dewa Ruci. Penegrtian pramana dalam Serat Dewa Ruci serupa dengan Roh Suci. Dengan demikian menurut penafsiran Sumantri bahwa konsep Roh Suci sebagai faset ketiga yaitu penampakan diri Tuhan, identik dengan martabat wahidiyah. Di dalam serat Sasangka Jati juga terdapat penjelasan bahwa nur Muhammad identik dengan Suksma Sejati dan juga identik dengan Kristus, seperti kutipan berikut:

Tokoh Pangestu bernama Ny. Supandji menjelaskan bahwa Suksma Kawekas menurut ajaran Pangestu identik dengan Allah Ta'ala dalam Islam, yang serupa dengan Sumber Hidup, seperti yang dijelaskan bahwa setiap bangsa memberi nama kepada Sumber Hidup tersebut. Misalnya orang Arab menyebut Allah Ta'ala, orang Yunani menyebutnya Deo, orang Inggris God, orang Tionghoa Thian, orang jawa dalam bahasa Jawa Kuno sebagai Suksma Kawekas. Menurut Supandji, Suksma Kawekas merupakan Sumber Hidup, yang memiliki potensi Mahabesar, Mahakuasa, dan maha segala-galanya. Hal ini disebut Tuhan dalam keadaan laten, dalam kondisi laten tersebut, manusia tidak dapat merasakan kebesaran Tuhan. ${ }^{23}$

Dari penjelasan Ny. Supandji di atas disebutkan bahwa Suksma Kawekas identik dengan Allah Ta'ala. Hal ini sejalan dengan keterangan yang terdapat dalam serat Sasangka Jati, bahwa Suksma Kawekas (Tuhan Sejati), kata Arabnya Allah Ta'ala. ${ }^{24}$ Suksma Kawekas juga identik dengan Sumber Hidup, sejalan dengan Sabda Pratama bahwa semua sifat Hidup berasal dari Suksma Kawekas, yaitu Tuhan semua makhluk yang ada. Sukma kawekas merupakan letak sesembahan yang sejati, adalah Sumber Hidup, dimana semua mahluk yang ada akan kembali kepada-Nya. ${ }^{25}$

Dari penjelasan di atas sangat jelas bahwa Suksma Kawekas itu serupa dengan Allah Ta'ala, dan serupa dengan Sumber Hidup. Bahwa roh suci merupakan faset ketiga dari penampakan diri Tuhan dan identik dengan martabat wahidiyat. Suksma Sejati sebagai faset kedua serupa dengan martabat wahdat. Dari sini dapat disimpulkan bahwa Suksma Kawekas sebagai faset pertama penampakan diri Tuhan, sama dengan martabat ahadiyah.

Tentang hal ini Sumantri menggunakan perumpamaan atau simbol dalam penjelasannya. Seperti air, Suksma Kawekas air yang sedang diam. Suksma Sejati merupakan air yang sedang bergerak dari air yang diam tersebut. Sedangkan Roh Suci seperti titik-titik air yang menguap dari air tersebut. Penggunaan simbol-simbol samudera dan matahari untuk menggambarkan ajaran Tri Purusa tersebut telah digunakan jauh sebelumnya oleh para sufi besar. Ibn al-'Arabi dan Hamzah Fansuri dari Pasai telah terlebih dahulu menggunakan simbol-simbol tersebut.Hamzah Fansuri menggunakan lautan dan deru ombak untuk menjelaskan ajaran wujudiyah tentang penampakan diri (tajalli) Tuhan. Hamzah Fansuri mengatakan bahwa ta'ayyun awwal seperti laut, apabila laut tersebut bergerak maka ombak namanya, apabila 'alim memandang dirinya maka ma'lum jadinya. Apabila laut tersebut melepas nyawa, maka asap

\footnotetext{
${ }^{23}$ Suwarno Imam S, Konsep Tuhan..., h. 305.

${ }^{24}$ R. Soenarto Mertowardojo, Sasangka Jati, h.13.

${ }^{25}$ R. Soenarto Mertowardojo, Sasangka Jati, h.2.
} 
namanya, yaitu dirinya nyawa dengan roh idlofi a'yan tsabitah sekalian. Apabila asap tersebut berhimpun di udara, maka awan namanya, yaitu isti'dad awan a'yan tsabitah berhimpun hendak keluar. Apabila awan tersebut titik di udara, maka hujan namanya, yakni roh idlofi dengan a'yan tsabitah keluar dengan ucapan/qaul kun fayakun berbagai-bagai namanya. Apabila hujan tersebut hilir di bumi, sungai namanya, yaitu setelah roh idlofi dengan istidad asli dengan a'yan tsabitah hilir di bawah kun fayakun 'alim namanya. Apabila sungai tersebut pulang ke laut hukumnya tetap laut itu Mahasuci tiada lebih atau kurang. Apabila keluar sekalian maka tiada kurang, sebaliknya jika ada yang masuk jug a tiada lebih. karena ia suci daripada sekalian suci.

Allah-Rasul-Muhammad atau Sang Rama-Sang Putra-Roh Suci, atau Suksma KawekasSuksma Sejati-Roh Suci tidak dipandang berada dalam berdampingan, melainkan merupakan tingkatan yang sejajar dengan martabat tajalli Tuhan, seperti ahadiyah, wahdah, dan wahidiyah. Seperti tingkatan emanasi dalam Neoplato-nisme, seperti Tuhan, roh alam, dan jiwa alam. ${ }^{26}$

Penafsiran Sumantri tentang Tri Purusa di atas juga serupa dengan teori emanasi yang disederhanakan. Konsep emanasi ini lebih sederhana terdapat dua prinsip, yaitu prinsip beremanasi dan emanasi itu sendiri atau menurut tiga prinsip yaitu Tuhan, Nur Muhammad (Roh Ilahi), dan dunia. Pendapat Zoetmulder tentang teori emanasi tersebut adalah hubungan antara Zat dan sifat, misalnya dijumpai dalam Niti Mani. Dalam Niti Mani ... terdapat frasa sebagai berikut: dene nugraha punika dat ing, gusti kanugrahan puniko sipating kawula. Hubungan antara dat ing gusti-sipat ing kawula bersifat eksplikatif, sehingga apabila diterjemahankan berbunyi, dia yang menganugerahkan dirinya sendiri, adalah zat, yakni zat Tuhan, dia yang menerima anugerah adalah sifat, yaitu sifat kawula. Frasa ini ditafsirkan menurut teori emanasi yang disimpulkan dari kalimat yang mendahuluinya.Dari frasa ini Nabi Muhammad adalah sipat ing cahya kita pribadi, yakni sifat cahaya karni (Tuhan) yang terpancar dari zatNya. Oleh karena itu Nabi Muhammad dinamakan utusan= rasul. ${ }^{27}$

Berkaitan dengan konsep manusia menurut Pangestu juga telah di terangkan dalam kitab Sasangka Jati.Kitab Sasangka Jati menerangkan bahwa Tuhan mempunyai Kehendak menurunkan roh suci sebelum dunia ini tercipta. Sebelum dunia tercipta, Tuhan mempunyai Kehendak menurunkan roh suci, berupa cahaya Tuhan. Kehendak tersebut terhenti dikarekan belum ada kancah dan tempat bersemayamnya. Oleh karena itu Tuhan kemudian menciptakan dunia. ${ }^{28}$ Sumantri menafsirkan hal tersebut sebagai berikut, yaitu di dalam Kesadaran Agung yang diam tersebut terkandung Kehendak untuk melepaskan cahaya-cahaya, sebagai pletikan api dari api Yang Maha agung. Namun cahaya-cahaya tersebut belum ada kancahnya. Cahaya-cahaya tersebut dilepaskan dari dan oleh Suksma Sejati. ${ }^{29}$ Pendapat tersebut menunjukkan bahwa penurunan roh suci berasal cahaya Tuhan. Penciptaan roh suci oleh Sumantri digambarkan seperti pletikan api yang berasal dari api Yang Mahaagung. Roh suci tersebut sebagai cahaya Tuhan, yang sebelumnya bertunggal dengan Suksma Sejati.Kemudian cahaya tersebut dipancarkan dari Suksma Sejati. Dari penjelasan tersebut membuktikan bahwa penciptaan manusia melalui proses emanasi.

\footnotetext{
${ }^{26}$ Suwarno Imam S, Konsep Tuban..., h. 307.

${ }^{27}$ Suwarno Imam S, Konsep Tuhan..., h. 309.

${ }^{28}$ R. Soenarto Mertowardojo, Sasangka Jati, h.47.

${ }^{29}$ Suwarno Imam S, Konsep Tuhan..., h. 310.
} 
Pada saat roh suci belum turun ke dunia, Tuhan telah memberikan kesaksian berupa pahugeran, yaitu setelah roh suci memakai anasir jasmani senantiasa sadar asal usulnya, bahwa roh suci berasal dari Tuhan dan harus kernbali kepada-Nya.menurut sumantri Pahugeran tersebut merupakan perjanjian agung. Seperti kutipan berikut ini: Suksma Kawekas tersebut tetap menjadi pujaan hamba yang sejati sedang Suksma Sejati itu tetap menjadi utusan Tuhan Sejati, serta menjadi penuntun dan guru hamba yang sejati. Hanya Suksma Kawekas pribadi yang menguasai seluruh alam seisinya, hanya Suksma Sejati pribadi yang menuntun para hamba semua. Semua kekuasaan, adalah kekuasaan Sukstna Kawekas, itu berada dalam kekuasaan Suksma Sejati (Soenarto:153). Sumantri menyatakan bahwa Intisari pahugeran Tuhan kepada roh suci (hamba) tersebut identik dengan "syahadat" agama Islam. ${ }^{30}$

Asal mula terjadinya manusia dari cahaya bertunggalnya Tri Purusa: Suksma Kawekas, Suksma Sejati, Roh Suci, yang diberi silimut sari dari anasir empat, yaitu: udara, api, air, dan tanah. kemudian lahir menjadi bahan kasar (lahir) dan halus (batin). Badan jasmani diberi peralasan berupa pancaindra, meliputi penglihatan, pendengaran, pengucapan, pencium, dan perasa. Kemudian diberi saudara yang dinamakan nafsu empat, meliputi: lawwamah, amarah, sufiah, mutmainah, dan kemudian diberi lagi tiga saudara. Tiga saudara ini berkumpul menjadi satu di angan-angan, yang dinamakan pangaribawa, prabawa, dan kemayan. ${ }^{31}$ Menurut Kitab Suksma Sejati terjadinya manusia dari cahaya Tri Purusa yang kemduian diberi pakaian berupa empat anasir air, tanah, api, udara, kemudian dilengkapi dengan peralatan badan jasmani, berupa lima pancaindra, empat nafsu, dan tiga angan-angan. Oleh karena sering dikatakan manusia mempunyai tujuh saudara, yaitu empat saudara atau empat nafsu, dari halusnya empat anasir, dan tiga saudara lainnya dari bayangan Tri Purusa.

Menurut Sasangka Jati, proses penciptaan manusia, ang diciptakan pertama kali adalah empat macam anasir, udara, api, air, dan bumi. Empat anasir ini, walaupun atas kekuasaan Tuhan namun juga berasal dari Tuhan, diibaratkan pelita dan asapnya. Misalnya Tuhan tersebut sebuah pelita, maka asapnya adalah anasir yang empat tersebut. ${ }^{32}$ Penjelasan tersebut jelas bahwa proses penciptaan empat macam anasir berupa udara, api, air, dan bumi sama yaitu melalui proses emanasi. Terciptanya empat macam anasir itu atas kehendak Tuhan, ibarat pelita dan asapnya. Seperti Tuhan sebagai pelita, dan anasir adalah asapnya. Proses penciptaan secara emanasi ini dijelaskan oleh Sumantri dalam bentuk perumpamaan atau symbol. ${ }^{33}$ Simbol tersebut adalah Suksma Kawekas ibarat samudra yang diam, airnya tenang, kemudian bergerak yang memunculkan gelombang. Gelombang tersebut dibaratkan sebagai Suksma Sejati. Sedangkan Roh Suci adalah seperti titik-titik air yang menguap dari air samudra yang luas itu. ${ }^{34}$ Sedangkan Hamzah Fansuri menggambarkan tentang proses penciptaan manusia sebagai berikut. Allah ibarat laut yang dalam, airnya tenang. Air laut yang luas, tenang tersebut timbul ombak. Ombak yang muncul tersebut menjadikan timbul uap naik, menjadi mendung.

\footnotetext{
${ }^{30}$ Suwarno Imam S, Konsep Tuhan..., h. 310.

${ }^{31}$ Suwarno Imam S, Konsep Tuhan..., h. 311.

${ }^{32}$ R. Soenarto Mertowardojo, Sasangka Jati, h.107.

${ }^{33}$ Suwarno Imam S, Konsep Tuban..., h. 312.

${ }^{34}$ R. Soemantri Hardjoprokoso, Wabyu Sasangka Jati, (Jakarta: Proyek Penerbitan dan Perpustakaan Pangestu Pusat,
} 1977), h. 6. 
Kemudian dari mendung tersebut turun hujan yang membasahi bumi. Hujan membasasi bumi mengalir menjadi sungai, yang kembali ke laut kembali. ${ }^{35}$

Sebelum dunia ini diciptakan, Tuhan berkehendak menurunkan roh suci. Berarti Kehendak Tuhan menurunkan roh suci ke dunia merupakan tujuan yang utama dibanding dengan penciptaan dunia itu sendiri. Penjelasan ini identik dengan pendapat Hamzah Fansuri.Menurut Hamzah Fansuri tujuan terakhir pengaliran ke luar Zat Ilahi adalah untuk menunjukkan kesatuan Allah dan manusia.Aliran terakhir yang keluar dari Zat Ilahi yang terpenting. Manusia adalah mahkota dan puncak alam semesta diciptakan. Walaupun aliran yang ke luar terakahir adalah manusia atau yang teraakhir dilahirkan ke luar, namun dalam kehendak pikiran Allah manusia adalah yang pertarna.Pendeknya ketika Allah mengalirkan diri, maka yang pertama-tama tujuanNya ialah manusia. ${ }^{36}$

Kemudian empat nafsu itu juga terjadi melalui proses emanasi, yaitu dari halusnya empat anasir. Sebab halus empat anasir hanya berwujud cahaya yang memiliki warna sendiri-sendiri, yang semuanya terjadi bersamaan.Yaitu ketika roh suci turun ke dalam kandungan ibu.Dari tujuh saudara yang ada dalam diri manusia yang empat dari halusnya empat macam anasir tersebut. $^{37}$

Tentang tiga angan-angan berasal dari bayangan Tri Purusa dijelaskan dalam serat Sasangka Jati, yaitu bahwa Saudara pangaribawa, prabawa, dan kemayan terjadi dari bayangan Tri Purusa sebagai Akunya manusia. Merupakan kekuasaan yang dianugerahkan, untuk dapat dipakai memerintah keempat saudara yang lain, dengan maksud agar selaras dengan Kehendak Tuhan. ${ }^{38}$

Menurut Sumantri empat nafsu dari empat anasir, adalah : (1) nafsu lawwamah yang terjadi dari anasir bumi, nafsu ini berada di daging manusia. Watak dari lawwamah adalah nista, tamak, loba, dan malas. Nafsu lawwamah merupakan hasil dari dorongan egoisme, mencari selamat diri sendiri dan enggan bertindak.Nafsu ini dalam sifat ingin mencari enaknya, puas diri, dan nafsu sahwat. (2) nafsu amarah berasal dari anasir api, tempat berada merata di darah seluruh tubuh manusia. Watak amarah berupa keras, pemarah dan cepat patah hati. Nafsu Amarah menjadi jalan bagi nafsu lain, baik untuk berbuat hal buruk atau hal yang baik. ${ }^{39}$

Ketiga, nafsu sufiah berasal dari anasir air, tempatnya berada di sumsum Watak nafsu Sufiah, adalah keinginan asmara dan birahi. Nafsu sufiah adalah nafsu yang berpran memunculkan hasrat cinta kasih dan yang indah. Keempat, adalah nafsu mutmainah. Nafsu ini berasaldari unsur suasana atau udara. Nafsu ini berada dalam napas. Watak nafsu mutmainan adalah terang, suci, bakti, dan welas asih.NafsuMutmainah berperan memberi dorongan ke arah sosial, perikemanusiaan, dan cinta kepada sesame. ${ }^{40}$

Sedangkan angan-angan adalah bayangan atau refleksi dari Tri Purusa, yang di dalam selubung jasmani adalah daya-daya intelektual manusia. Refleksi tersebut terdiri dari tiga aspek, yaitu cipta, nalar, dan pangerti.Ketiga hal ini memiliki fungsi masing-masing. Cipta memiliki

\footnotetext{
${ }^{35}$ Harun Hadiwijono, Konsep Tentang Manusia..., h. 60.

${ }^{36}$ Suwarno Imam S, Konsep Tuhan..., h. 313.

${ }^{37}$ R. Soenarto Mertowardojo, Sasangka Jati, h. 61-62.

${ }^{38}$ R. Soenarto Mertowardojo, Sasangka Jati, h.62.

${ }^{39}$ Suwarno Imam S, Konsep Tuban..., h. 314.

${ }^{40}$ R. Soemantri Hardjoprokoso. Wabyu Sasangka Jati, h. 177.
} 
fungsi menangkap atau membayangkan suatu hal, nalar memiliki fungsi mengasosiasikan atau mmenghubungkan berbagai bayangan, dan pengerti memiliki fungsi menyimpulkan semua hal yang dibayangkan. Masing-masing aspek tersebut merupakan pantulan dari Tri Purusa.Daya Cipta merupakan pantulan roh suci, nalar merupakan pantulan dari Suksma Sejati, dan pangerti merupakan pantulan Suksma Kawekas.

Manusia dianugerahi "saudara tiga" yang menjdi satu berkumpul dalam angan-angan adalah sesuai dengan Kehendak Tuhan, maksudnya adalah agar manusia mengendalikan "saudara empat" atau empat nafsu lainnya tersebut. Maka, kekuasaan Aku-manusia tersebut harus senantiasa harus dapat menjalin hubungan dengan nafsu mutmainah agar dalam mengendalikan ketiga nafsu lawwamah, amarah, suftah berhasil diatasi menuju kepada hal yang baik atau utama. ${ }^{41}$

Kekuasaan dari angan-angan dalam hidup sehari-hari berpusat kepada Aku atau Ego manusia.Aku merupakan pusat pimpinan jiwa manusia yang meliputi angan-angan, perasaan, dan nafsu.Namun angan-angan yang berpusat pada Aku (Ego) tersebut bukan merupakan jiwa manusia sejati, atau bukan roh suci, tetapi hanya merupakan bayangan Tri Purusa. Maka kekuasaan angan-angan yang diberikan Tuhan, agar dipakai untuk rnengendalikan empat nafsu lainnya, dengan maksud agar selaras dengan Kehendak Tuhan. Apabila pusat atau imnpinan jiwa (psyche) disebut Ego (Aku), hanya berhubungan dengan hidup sehari-hari. Jiwa manusia yang sejati atau roh suci tersebut adalah atau disebut Super Ego. ${ }^{42}$

Manusia yang percaya kepada Tuhan harus mengurangi kedaulatan Aku-nya (egosime) yang di dalam hatinya.Egoisme tersebut digerakkan agar menjadi percaya, sadar dan taat kepada Tri Purusa (Tuhan). Semakin seseorang mengurangi sifat ke-Akuan (Egoisme)-nya, maka akan semakin dekat dengan Tuhan. Namun sebaliknya, seseorang yang terpedaya permainan nafsu, maka semakin kuat sifat ke Aku-nya.Akibatnya semakin jauh dengan Tuhan.Pada dasarnya, semua sifat buruk cenderung memperkuat kedaulatan Aku, agar tidak tunduk kepada Tuhan.

Karenanya ketiga unsur jiwa berupa angan-angan, perasaan, dan nafsu harus berada di dalam satu kendali yang dipimpin oleh sang Aku. Dengan maksud agar ketiga unsur jiwa dapat selaras dan seimbang sesuai dengan kehendak Tuhan. Apabila unsure-unsur jiwa tersebut dapat selaras dan seimbang, hasilnya adalah jiwa manusia akan tenang, tenteram, dan bahagia. Untuk mencapai keselarasan dan keseimbangan diantara unsur jiwa tersebut, maka sebagai pimpinan ketiga unsur jiwa, sang Aku harus terus mengadakan hubungan dengan Tuhan, untuk dapat meningkatkan kemampuan, kekuasaan, dan kebijaksanaan dalam hidupnya. Dalam Pangestu bentuk hubungan sang Aku dengan Tuhan tersebut adalah Trisila, berupa sadar, percaya, dan taat kepada Tuhan. ${ }^{43}$

Panembah Tiga Tingkatan yaitu tahapan menyembah kepada Tuhan, terdiri atas:

a. Panembah raga kepada Roh Suci, merupakan tingkatan panembah bagi jiwa yang masih muda. Pada tingkatan ini Roh Suci berusaha mengalahkan empat nafsu, yakni lawwamah, amarah, sufiah, dan mutmainah

\footnotetext{
${ }^{41}$ Suwarno Imam S, Konsep Tuhan..., h. 315.

${ }^{42}$ Harun Hadiwijono, Konsep Tentang Manusia..., h. 126.

${ }^{43}$ Suwarno Imam S, Konsep Tuhan..., h. 316.
} 
b. Panembah Roh Suci kepada Suksma Sejati, merupakan tingkatan panembah untuk jiwa yang telah dewasa. Pada tahapan ini Roh Suci berhasil menundukkan hawa nafsu dan Roh Suci berusaha taat kepada Suksma Sejati

c. Panembah Suksma Sejati kepada Suksma Kawekas merupakan tingkatan panembah bagi jiwa yang telah luhur budi. Pada tingkatan ini panembah merupakan jalan untuk me-tunggal dengan Tuhan. ${ }^{44}$

\section{Shalat sebagai Sembahyang kepada Allah}

Spiritualitas dalam agama Islam, tercermin dalam ibadah shalat yang merupakan laku menyembah kepada Tuhan. Ibadah shalat di pergunakan sebagai pembanding untuk menganalisis konsep panembah menurut aliran Pangestu dan Sumarah. Dalam Islam (terutama tasawuf)pada dunia batin dan rasa, ibadah, tingkah laku dan terkait dengan tujuan manusia, yaitu Allah swt. Dalam menjelaskan hubungan dengan Tuhan ini, para sufi mempunyai bahasa yang berbeda dibandingkan dengan bahasa yang tertulis. Seringkali bahasa yang digunakan para sufi hiperbola yang berfungsi ganda, yaitu menyingkap sekaligus menyembunyikan. ${ }^{45}$ Bahasa sufimerupakan bahasa dzawq, rasa atau bahasa hati. Bahasa sufi dimaksudkan sebagai simbol untuk mewadahi secara sempurnamakna dan pengalaman yang dirasakan oleh para sufi. Karena bahasa mengandung keterbatasan untuk mengungkan makna yang dirasakan oleh pengalaman religius tersebut. Pengalaman ruhani merupakan dimensi tanpa batas, atausebuah samudera tanpa pantai. Alam semesta yang terbatas adalah ayat-ayat (tanda-tanda) dari adanya Allah Yang Maha Tidak Terbatas. Demikian Gulen meminjam ungkapan ibn 'Arabi. ${ }^{46}$

Ibadah dalam Islam tidak sekedar menjalankan ritus-ritus yang diwajibkan seperti ibadah shalat, puasa, zakat, dan haji. Ibadat dalam pengertian Islam adalah berserah diri hanya kepada Allah swt. melaksanakan perintah dan larangan-Nya yang termaktub dalam ketentuan yang telah ditetapkan dalam kitab suci. Dalam Islam ibadah ritual dalam bentuk shalat yang didalamnya terdapat tata cara seperti yang terdapat rukun dan syarat sahnya shalat. Tata cara yang terkait fisik seperti gerakan-gerakan shalat, berdiri, takbir, rukun, sujud. Di samping gerakan fisik terdapat doa, karena shalat pada dasarnya adalah doa. Dari doa itulah shalat sebagai, ibadah yang yang penuh makna. ibadah shalat terdapat dimensi ruhani ritus dan jasmani sebagai hal yang tak terpisahkan. ${ }^{47}$ Aspek lahir, ibadah dalam Islam sangat menarik perhatian kalangan non-muslim. Seperti ajakan untuk melakukan shalat melalui adzan yang dilakukan bersama berupa sekumpulan orang yang tersusun dalam deretan(bershaf-shaf), membungkukkan badan atau rukuk secara bersamaan, kemudian sujud secara bersamaan). Gerakan-gerakan shalat tersebut dilakasanakan seragam dan serempak.

Adapun makna shalat yang mencakup hakikat, dan jiwa shalat adalah hati menghadap kepada Allah sang pencipta, menghadap kehadirat-Nya dengan peraasaan takut, cinta, tenteram, menumbuhkan rasa kebesaran-Nya, dengan berserah total kepadaNya, secara khusyuk dan ikhlas. Dilasanakan melalui perkataan dan perbuatan, yang gerakan dimulai dengan takbir dan

\footnotetext{
${ }^{44}$ R. Soenarto Mertowardojo, Sasangka Jati, h. 272.

${ }^{45}$ Fathullah Gulen, Kunci-Kunci Rahasia Sufi, (Jakarta: Srigunting, 2001), h.vi.

${ }^{46}$ Fathullah Gulen, Kunci-Kunci Rahasia Sufi, h. vii.

${ }^{47}$ Imam al-Ghazali, Ibadab Perspektif Sufistik, (Surabaya: Risalah Gusti, 1999), h. vii.
} 
diakhiri dengan salam. ${ }^{48}$ Di dalam ajaran Islam, shalat merupakan salah satu rukun Islam yang wajib dilakukan oleh setiap muslim. Karena sebagai kewajiban maka shalat tidak boleh ditinggalkan Dalam shalat terjadi komunikasi dengan Allah dan berakhir dengan memperhatikan sesama manusia. Dalam berkomunikasi dengan Tuhan ditandai dengan takbir, dan doa-doa dalam shalat lainnya, sedangkan setelah shalat ditandai dengan salam. Salam ini merupakan bentuk komunikasi dengan dalam dimensi horisontal yang sebelumnya didahului dengan komunikasi Ilahi. Salam di akhir shalat tidak sekedar ucapan tetapi simbol untuk memperhatikan lingkungan Setelah shalat maka hubungan manusia harus dilaksanakan dengan baik. Dalam salam menengok ke kanan dan ke kiri merupakan simbol bahwa setelah shalat perbuatan baik harus dilaksanakan. Demikianlah kepribadian muslim sejati dibangun melalui keadaan dan suci, lahir maupun batin. Kesucian lahir dilaksanakan denganwudhu sebelum shalat (Q.S. al-Maidah: 6), sedangkan kesucian batin diperoleh melalui sikap ikhlas dan khusyuk (Q.S. al-Mu'minun: 12). Dalam shalat adanya konsentrasi dan diharamkan mengkonsumsi hal-hal yang memabukkan seperti minuman keras, (Q.S. an-Nisa: 43). Begitu pula dalam shalat keserasian dan kebersamaan, tercermin dari barisan (shaf), bacaan amin oleh makmum setelah iman selesai membaca surat al-Fatihah. ${ }^{49}$

\section{Penutup}

Shalat dan laku manembah dalam kebatinan Sumarah dan Pangestu merupakan sarana untuk mendekatkan diri sedekat-dekatnya. Dalam ajaran Sumarah disebutkan pada tingkatan sujud yang paling sempurna saat jumbuhing kawula Gusti sudah menjadi sujud di dalam hidup, dimana tidak terdapat pihak yang bersujud dan pihak yang disujudi, karena telah menjadi satu. Sedangkan dalam ajaran Pangestu saat Panembah Suksma Sejati telah mencapai kepada Suksma Kawekas saat itulah terjadi penyatuan antara yang menyembah dengan Tuhan.

\section{DAFTAR PUSTAKA}

Arsip Sardjana Budi Santoso. (1973). Jakarta: Proyek Penerbitan dan Perpustakaan Pangestu Pusat.

- (1987). Sabda Khusus. Jakarta: Paguyuban Ngesti Tunggal.

- (1988). Sabda Pratama. Jakarta: Paguyuban Ngesti Tunggal.

(1984). Taman Kamulyan Langgeng. Jakarta: Paguyuban Ngesti Tunggal.

(1976). Olah Rasa di Dalam Rasa (Bisikan Sukma). Jakarta: Proyek Penerbitan dan Perpustakaan Pangestu Pusat.

-. (1977). Pokok-Pokok Pilangwangipun Sang Guru Sejati Utawi Suksma Sejati. Jakarta: Pangestu.

Ahmad, Khursyid. (1983) Pesan Islam, terj. Achsin Muhammad. Bandung: Pustaka Salman ITB. al-Ghazali, Imam. (1999). Ibadah Perspektif Sufistik, Surabaya: Risalah Gusti.

Any, Anjar. (1985). Menyikap Serat Wedatomo, Semarang: CV. Aneka.

Ash-Shiddiqi, T.M. Hasbi. (1993). Pedoman Shalat, Jakarta: Bulan Bintang.

\footnotetext{
${ }^{48}$ T.M. Hasbi Ash-Shiddiqi, Pedoman Shalat, (Jakarta: Bulan Bintang, 1993), h. 64.

${ }^{49}$ Abdul Mujib, Fitrah dan Kepribadian Mislam : Sebuah pendekatan Psikologis, (Jakarta : Darul Falah, 1999), h. 197.
} 
Daradjat, Zakiah. (1991). Ilmu Jiwa Agama, Jakarta: Bulan Bintang.

El Hafidy, M. As'ad. (1982). Aliran-Aliran Kepercayaan dan Kebatinan di Indonesia, Jakarta: Ghalia Indonesia.

Gulen, Fathullah. (2001). Kunci-Kunci Rahasia Sufi, Jakarta: Srigunting.

Hadikusuma, Djarnawi. (1982). Kristologi, Yogyakarta: Percetakan Persatuan.

Hadiwijono, Harun. (1987). Kebatinan dan Injil, Jakarta: BPK Gunung Mulia.

Hardjoprakoso, R.T. dan R. Trihardono Soemodihardjo. (1976). Ular-Ularpun Juru Mengeti, Jakarta : Proyek Penerbitan dan Perpustakaan Pangestu Pusat.

Hardjoprokoso, R. Soemantri. (1977). Wabyu Sasangka Jati, Jakarta: Proyek Penerbitan dan Perpustakaan Pangestu Pusat.

Hidayat Komaruddin. (2000). Tuhan Begitu Dekat, Jakarta: Paramadina.

Ilyas, Abd. Muthalib dan Abd.Ghofur Imam. (1988). Aliran Kepercayaan dan Kebatinan di Indonesia, Surabaya: CV. Amin

Kamal, Musthafa. (1985) Fikih Islam I dan II, Yogyakarta: Persatuan.

Malkhan, Abd. Munir (Ed). (1987). Kebatinan dan Dakwah Kepada Orang Jawa, Yogyakarta: Percetakan Persatuan.

Mertowardojo, R. Soenarto. (1983). Sasangka Jati, Jakarta: Badang Penerbitan dan Perpustakaan Pangestu Pusat.

Muhadjir, Noeng. (1990). Metodologi Penelitian Kualitatif, Yogyakarta: Rake Sarasin.

Mujib, Abdul dan Jusuf Mudzakir. (2001), Nuansa-Nuansa Psikologi Islam, Jakarta: Rajawali Press.

Mujib, Abdul. (1999). Fitrah dan Kepribadian Islam: Sebuah pendekatan Psikologis, Jakarta: Darul Falah.

Nazir, Moh. (1985). Metode Penelitian, Jakarta: Ghalia Indonesia.

Poerwadaminta, W.J.S. (1984). Kamus Umum Bahasa Indonesia, Jakarta: Balai Pustaka.

Rahardjo, R. (1974). Riwayat Hidup Bapak Paranpara R. Soenarto Mertowardojo, Jakarta: Proyek Penerbitan dan Perpustakaan Pangestu Pusat.

Rahman, Fazlur.( 1983). Tema Pokok Al-Qur'an, terj. Anas Mahyudin. Bandung: Pustaka Salman ITB.

“Ratusan Jalan Mencari Tuhan”, Tempo, No. 29 Tahun XVII, 29 September 1987

Razak, Nasruddin. (1989). Dienul Islam, Bandung: Al-Ma’arif.

Soedjarwo. "Tunggal Sabda Sebagai Landasan Untuk Mencapai Tujuan Akbir Menyiswa Bertunggal Dengan Sang Guru Sejati)". Dwija Wara. Tahun XXXIV, No. 3, Juli, 1990, dan No. 4, Agustus, 1990.

Sopater, Sularso. (1987). Mengenal Pokok-Pokok Ajaran Pangestu, Jakarta: Sinar Harapan.

Sou'yb, Josesoef. (1988) Aliran Kebatinan (Mistik) dan Perkembangannya, Medan: CV. Rinbow.

Sururin. (2000). Rabi'ah Al-Adawiyah Hubb Al-Illabi: Evolusi Jiwa Manusia Menuju Mahabbah dan Makrifah, Jakarta: Srigunting.

Titus, Harold., Smith, Marilyn, and Nolan, Richard. (1974). Living Issues in Philoshopy, New York: D. Van Nostrand Company. 